\title{
The Industrial Athlete and Flexibility
}

\author{
John Amtmann ${ }^{1 *}$ and Sophie Hegg ${ }^{2}$ \\ ${ }^{1}$ Applied Health and Safety Science, Montana Tech, USA \\ 2Industrial Hygiene, Montana Tech, USA
}

\begin{abstract}
Prevention of health and medical problems requires the ability to look further into the future than the average American is used to, but it's worth it. Flexibility is a basic component of health and fitness that may be part of the overall recipe required to prevent injuries such as sprains and strains, and can help to alleviate muscle soreness common in the American worker. Working Americans should be thought of as industrial athletes, and flexibility exercises may reduce the likelihood of injury to muscle tendon units. Along with the possibility of reducing the occurrence of injury, properly performed stretching exercises may help to relieve low back pain, muscular cramps, and muscular soreness and reduce stress.
\end{abstract}

\section{Introduction}

The average cost of a back injury related workers comp claim is approximately $\$ 60,000$ per employee [1]. Prevention of health and medical problems requires the ability to look further into the future than the average American is used to, but prevention is worth it. Flexibility is a basic component of health and fitness that may be part of the overall recipe required to prevent injuries such as sprains and strains, and can help to alleviate muscle soreness common in the American worker. American workers should be treated like athletes; they should be physically conditioned for two reasons, (1) to prevent injury at work and (2) to improve performance. Preventing athlete injury is the top priority for all coaches, and preventing injury to the American worker should be the top priority for all American employers. This article will address musculoskeletal flexibility, which is just one aspect of worker health and safety.

\section{Flexibility}

Flexibility can be defined as the range of motion of a joint or group of joints, and various factors determine joint range of motion [2]. One factor effecting range of motion is the architecture of the joint. The specific design of the bones that meet in the joint have a significant effect on the direction and range of motion at that joint. For example, the hinge joint of the elbow allows for relatively modest movement when compared to the ball and socket joint of the shoulder because of their respective architecture. Age and sex also play a role: younger people tend to be more flexible than older people, and females tend to be more flexible than males - especially in the hips. Also, active people tend to be more flexible than inactive people. Connective tissue, such as tendons, ligaments, fascial sheaths, joint capsules, and skin also determine joint range of motion.

Working Americans should be thought of as industrial athletes because their day to day function is related to physical health, and most strength and conditioning specialists stress the importance of the flexibility training for their athletes, believing flexibility exercises may reduce the likelihood of injury to muscle tendon units [3-5].

Some research supports this. In one study, researchers assessed the lower body flexibility in 146 male soccer players prior to the 1999-2000 seasons [6]. All of the examined players were monitored throughout the season to determine the presence and severity of injury. Players who suffered a hamstring $(\mathrm{N}=31)$ or quadriceps $(\mathrm{N}=$ 13) muscle injury during the season were found to have significantly lower flexibility in these muscles before their injury compared with the uninjured group. No significant differences in muscle flexibility were found, however, between players who sustained an adductor muscle injury $(\mathrm{N}=13)$ or a calf muscle injury $(\mathrm{N}=10)$ and the uninjured group.

Researchers concluded that these results indicate that soccer players with an increased tightness of the hamstring or quadriceps muscles have a higher risk for a subsequent musculoskeletal injury to those areas, but not necessarily to the groin or calf areas.

So, there is conflicting reports on the relationship between flexibility and injury. Most experts agree, however, that there appears to be an ideal range of flexibility that will help to prevent injury, and that flexibility may be one factor of many involved in the development of an injury. Injuries are, often, the result of both intrinsic and extrinsic factors. Intrinsic causes include age, weight, and overall physical fitness. Extrinsic factors would include dimensions (size and weight) of object being lifted, working terrain, and environmental factors such as weather [7].

As industrial athletes, Americans need flexibility training on a regular basis. Along with the possibility of reducing the occurrence of injury, properly performed stretching exercises may help to relieve low back pain, muscular cramps, and muscular soreness and reduce stress.

\section{Guidelines}

There are two general approaches to stretching: static and dynamic. Static stretching involves moving towards the body's limits of range of motion in a slow and gentle manner, and holding the stretched position. Dynamic stretching involves actively moving the limb toward the limits of its' range of motion. One type of dynamic stretching is called ballistic. As the name implies, ballistic stretching involves bouncing a limb towards the edge of its' range of motion. Static and dynamic stretching both may improve flexibility, but we recommend avoiding any ballistic stretching because these types of movements may actually increase the possibility of injury and excessive soreness [2].

When should you stretch? The body's temperature is usually higher

*Corresponding author: John Amtmann, Applied Health and Safety Science, Montana Tech, USA, Tel : 406-490-2558; E-mail: jamtmann@mtech.edu

Received December 12, 2016; Accepted March 08, 2016; Published March 15 2016

Citation: Amtmann J, Hegg S (2016) The Industrial Athlete and Flexibility. Primary Health Care 6: 220. doi:10.4172/2167-1079.1000220

Copyright: (c 2016 Amtmann J, et al. This is an open-access article distributed under the terms of the Creative Commons Attribution License, which permits unrestricted use, distribution, and reproduction in any medium, provided the original author and source are credited. 
at the end of a workout session compared to the beginning of the session, and this may be a safer and more effective time to stretch. So, following strength training session or a cardio session when body temperature is higher is a good time to do your stretches. However, the stretching could be done at any time during breaks in the work-day. The American College of Sports Medicine (ACSM) recommends the following guidelines (2000):

Type: A general stretching routine that exercises the major muscle and/or tendon groups.

Frequency: A minimum of 3 days per week

Intensity: Moving the body segment to a position of a comfortable stretch

Duration: $15-30$ seconds

Repetitions: 3 to 4 for each stretch

\section{A few important notes to be mindful of include the following}

- Some stretching exercises may not be appropriate for some participants because of prior injuries or other conditions, or because the exercises have been identified as unsafe. Avoid the contraindicated exercise shown below.

- Stretch to the point where you feel a comfortable stretch in the target muscle group, NOT pain. NO BOUNCING!

- Focus on deep breathing and avoiding breath holding. The recommended time, 15-30 seconds, should be spent concentrating on deep breathing and relaxing the muscle group being stretched.

If you want to make most effective use of your stretching time, make sure to target the common tight spots, which include the hamstrings, hips, quadriceps and low back but, keep in mind, research indicates that maintaining a healthy range of motion in all the joints/major muscle groups is important for preventing musculoskeletal injuries.

A common stretch that should be avoided is the hurdler's stretch. This stretch has been commonly used to target the hamstrings (when leaning forward) and the quadriceps (when leaning backward). The traditional form of this stretch causes external rotation of the flexed knee excessive stress to the medial collateral ligament of the knee $[8,9]$. There are a variety of modifications to safely adjust the hurdler's stretch, one modification is to bring the foot of the bent knee to the inside of the thigh rather than to the outside, and another is to hold the foot from behind with the opposite hand. Both modifications reduce the external rotation and the stress to the medial collateral ligament (Figures 1-6).

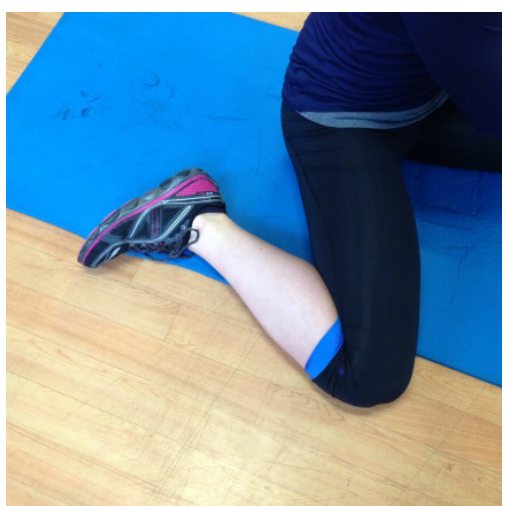

Figure 1: Hurdler's stretch.

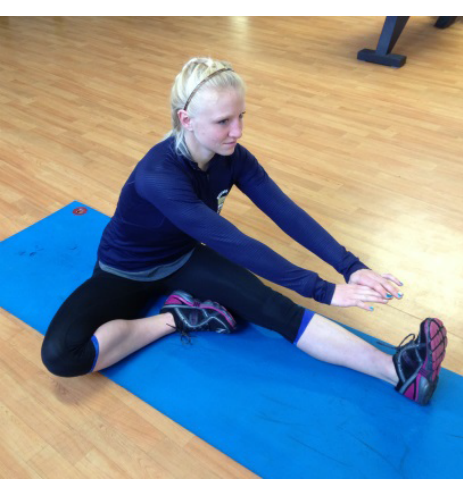

Figure 2: A safer alternative.

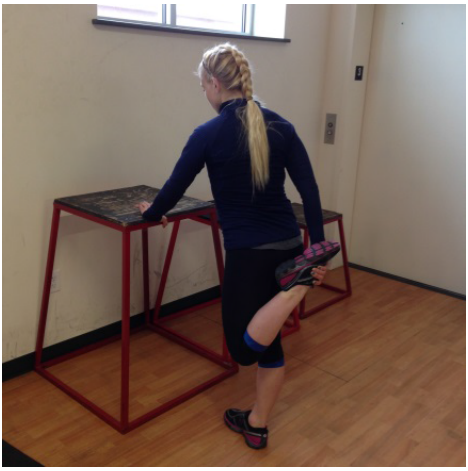

Figure 3: Another safe alternative.

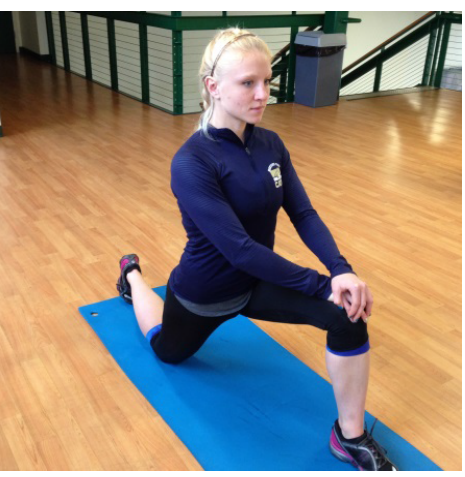

Figure 4: Hip flexor stretch.

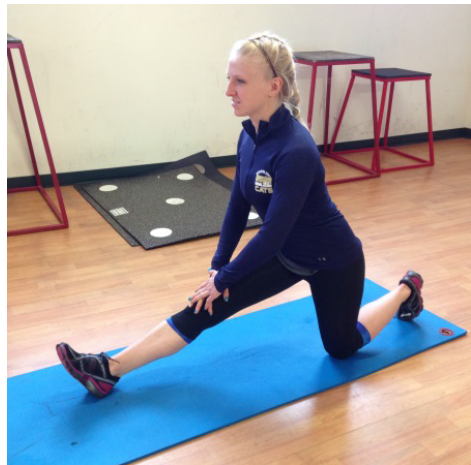

Figure 5: Hamstring stretch. 


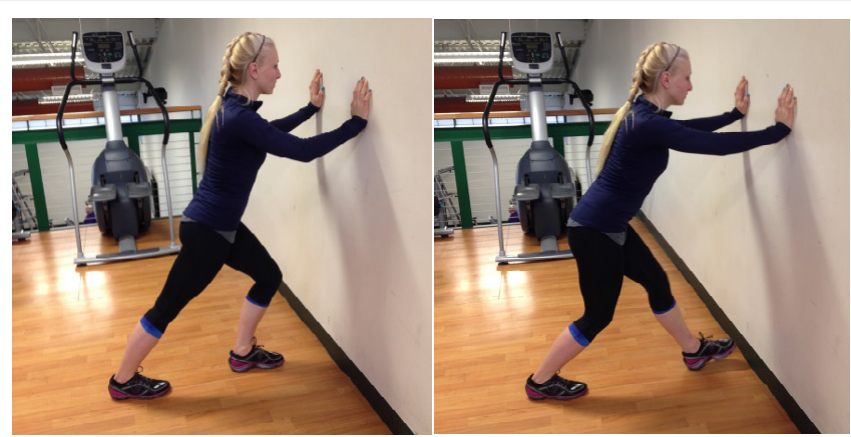

Figure 6: Gastrocnemius and Soleus stretch.

Remember, an ounce of prevention is worth a pound of cure, and developing health and fitness, including flexibility, will improve your chances of remaining injury free.

\section{References}

1. Encompass Group (2010) The Direct and Indirect Cost of Workplace Injuries.
2. Alter M (1996) Science of Flexibility. Second Edition. Champaign, IL: Human Kinetics.

3. Mannie K (2003) Flexible Perspectives on Stretching. Coach and Athletic Director7: 36-39.

4. Powers S, Howley E (2001) Exercise Physiology: Theory and application to fitness and performance. Fourth Edition. New York, NY: McGraw - Hill.

5. Vorkapic M (2002) Summer Strength and Conditioning Manual (Michigan State University).

6. Witvrouw E, Danneels L, Asselman P, D'Have T, Dirk C (2003) Muscle flexibility as a risk factor for developing muscle injuries in male professional soccer players: a prospective study. The American Journal of Sports Medicine 31: 4146.

7. Hackney R (1994) Nature, prevention, and management of injury in sport. (ABC of Sports Medicine). British Medical Journal 308: 1356-1359.

8. American College of Sports Medicine (2014) ACSM'S Resource Manual for Guielines for Exercise Testing and Prescription. Seventh Edition. Philadelphia: Lippincott Williams \& Wilkins.

9. American College of Sports Medicine (2005) ACSM's Guidelines for Exercise Testing and Prescription. Eighth Edition. Philadelphia: Lippincott Williams \& Wilkins. 